\title{
Problems in the prediction of protein values of diets
}

\author{
The influence of protein concentration
}

\author{
By D. S. MILLER AND P. R. PAYNE
}

Human Nutrition Research Unit, Nutrition Building, National Institute for Medical Research, Mill Hill, London, N.W. 7

(Received 29 fanuary I960-Revised 28 fuly 1960)

Platt \& Miller (1958) have pointed out that the net protein utilization (N.P.U.) of whole diets depends not only on the amino-acid composition of the proteins they contain but also on a number of other factors, the more important of which are: (I) the protein-calorie ratio of the diet, (2) the adequacy of the calorie intake and (3) the level in the diet of some vitamins and minerals.

It is difficult, therefore, to forecast the protein value of diets from analytical data on amino-acid composition. Some success has been achieved in predicting N.P.U. (standardized) at low levels of nitrogen intake from protein scores based on aminoacid analysis (FAO, I957), but when practical diets are considered it has been shown that N.P.U. (operative) is not directly related to the amino-acid content (Drury \& Miller, 1959). At present, therefore, the only means of assessing the protein value of practical diets is by biological assay of net dietary-protein value (N.D-p.v.), which is equal to N.P.U.(op.) multiplied by the protein content of the diet, and is a measure of utilizable protein (Platt \& Miller, 1959).

A solution to this problem may be provided by a series of equations showing the influence of the above dietary factors on protein value; this paper is concerned with the first of them, namely protein concentration, and it is hoped to deal with other factors in subsequent papers.

\section{EXPERIMENTAL AND RESULTS}

N.P.U. was determined on rats by the method of Miller $\&$ Bender (1955). For reasons outlined below we distinguish between N.P.U.(st.) measured at the lowest protein level sufficient to maintain nitrogen equilibrium in diets adequate in all other respects and N.P.U.(op.) measured under any other conditions in accordance with Platt \& Miller (1959). Calorific values were determined by the method of Miller \& Payne (1959).

\section{Expression of protein concentration}

It is usual to express the protein content of diets as a percentage of dry weight. We have preferred to characterize the diets used in this study in terms of the energy derived from protein as a percentage of the total energy because diets containing the same utilizable protein at equal energy content have the same dietary value despite possible wide differences in composition. Table I shows the results of feeding experiments with three diets containing different proportions of casein and fat. The figures 
indicate that the N.D.-p.v.'s, calculated on the basis of protein as a percentage of dry weight, range from 5.8 to 10.3 . However, the growth responses to the three diets were almost identical, as indicated by the figures in the table for nitrogen retained per rat per day and the mean rates of weight gain for groups of rats fed on these diets over a period of 5 weeks. The N.D-p.v.'s calculated on the basis of energy are in good agreement with the observed performance of the animals.

Table I. Effect of casein diets of equal net dietary-protein calories and varying composition on the performance of rats

\begin{tabular}{|c|c|c|c|c|c|c|c|}
\hline $\begin{array}{l}\text { Diet } \\
\text { no. }\end{array}$ & $\begin{array}{l}\text { No. of } \\
\text { rats }\end{array}$ & $\begin{array}{c}\text { Protein } \\
(\%)\end{array}$ & $\begin{array}{l}\text { Fat } \\
(\%)\end{array}$ & $\begin{array}{c}\text { N.D-p.v. } \\
\text { calculated } \\
\text { on a dry-wt } \\
\text { basis }\end{array}$ & $\begin{array}{c}\text { N.D-p.v. } \\
\text { calculated } \\
\text { on an energy } \\
\text { basis }\end{array}$ & $\begin{array}{l}N \text { retained } \\
\text { (g/rat day) }\end{array}$ & $\begin{array}{l}\text { Wt gain } \\
\text { (g/rat day) }\end{array}$ \\
\hline I & 20 & II'2 & 0 & 5.8 & 6.8 & 0.068 & $\mathrm{I} \cdot 8$ \\
\hline 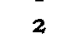 & 20 & 13.7 & I5 & $7 \cdot 5$ & $7 \cdot 2$ & 0.072 & 1.9 \\
\hline & 20 & 16.5 & 47 & 10.3 & $7 \cdot 2$ & 0.072 & $2 \% 0$ \\
\hline
\end{tabular}

Table 2. Values for $\mathrm{P}_{\mathrm{m}}$, N.P.U.(st.) and N.D-p.V. calculated on an energy basis for diets on which rats maintained body-weight to within $\pm \mathrm{I} g$ over a ro-day period

\begin{tabular}{|c|c|c|c|}
\hline Protein source & $P_{m}^{*}$ & N.P.U.(st.) & N.I-p.v.† \\
\hline Groundnut & $12 \cdot 2$ & $30 \cdot 3$ & $3 \cdot 70$ \\
\hline \multirow[t]{2}{*}{ Groundnut flour } & $9 \cdot 5$ & $35 \cdot 3$ & $3 \cdot 35$ \\
\hline & $9 \cdot 5$ & $43 \cdot 3$ & $4 \cdot 11$ \\
\hline \multirow{3}{*}{ Wheat gluten } & 10.0 & $43^{\circ} \circ$ & $4: 30$ \\
\hline & $10 \cdot 0$ & $42 \cdot 7$ & $4: 27$ \\
\hline & 9.9 & $39 \cdot 7$ & $3 \cdot 93$ \\
\hline \multirow{2}{*}{$\begin{array}{r}\text { Yeast I } \\
2\end{array}$} & $12 \cdot 5$ & $36 \cdot 7$ & 4.59 \\
\hline & $12 \cdot 0$ & $34 \cdot 2$ & $4 \cdot 10$ \\
\hline \multirow{4}{*}{$\begin{array}{l}3 \\
\text { Heated pork I } \\
2\end{array}$} & II. 6 & $37 \cdot 1$ & $4: 30$ \\
\hline & 9.5 & $28 \cdot 2$ & $2 \cdot 68$ \\
\hline & 8.0 & $52 \cdot 0$ & $4 \cdot I 6$ \\
\hline & $8 \cdot 0$ & $49 \cdot I$ & $3 \cdot 93$ \\
\hline Whale meal & $12 \cdot 7$ & $25 \cdot 6$ & 3.25 \\
\hline Kenya meat & II 10 & $38 \cdot 0$ & $4 \cdot 18$ \\
\hline Biltong & 12.5 & $38 \cdot 8$ & $4 \cdot 85$ \\
\hline & $3 \cdot 4$ & $73 \cdot 2$ & $2 \cdot 49$ \\
\hline $\begin{array}{l}\text { Egg albumin } \\
\text { Egg albumin }+ \text { glycine }\end{array}$ & 8.2 & $48 \cdot 4$ & 3.96 \\
\hline Whole egg & 3.6 & $102: 0$ & $3 \cdot 67$ \\
\hline \multirow{2}{*}{ Biscuit meal no. I } & II 4 & $37 \cdot 2$ & $4: 24$ \\
\hline & $10 \cdot 6$ & $43 \cdot 4$ & $4 \cdot 60$ \\
\hline \multirow{3}{*}{ Maize } & $\mathrm{II} \cdot 6$ & $48 \cdot 4$ & $5 \cdot 61$ \\
\hline & $9 \cdot 3$ & $36 \cdot 2$ & $3 \cdot 37$ \\
\hline & $9 \cdot 3$ & $31 \cdot 2$ & 2.90 \\
\hline \multirow[t]{2}{*}{ Leaf protein } & $10 \cdot 7$ & $42 \cdot 3$ & $4 \cdot 53$ \\
\hline & 10.5 & $42 \cdot 7$ & $4 \cdot 48$ \\
\hline
\end{tabular}

* $P_{m}$ represents the percentage of the energy in the diet supplied by protein and is equal to

$$
\frac{25 \mathrm{~N}(\text { in } \mathrm{g})}{\text { total kcal }} \% \text {. }
$$

$\dagger$ N.D-p.v. is expressed as a percentage throughout this paper. So also are $P_{m}$ and N.P.U.(st.). Hence the values of N.D-p.v. given here are obtained thus

$$
\text { N.D-p.v. }=P_{m} \times \text { N.P.U.(st) } \div \text { IOO. }
$$




\section{Maintenance N.D-p.V.}

In a diet fed $a d l i b$. the concentration of utilizable protein required to maintain body-weight was calculated from the results of routine assays. On twenty-five diets body-weight was maintained to within $\pm \mathrm{I}$ g over a ro-day period. The results of these assays are presented in Table 2. The protein contents of these diets supplied from 3 to $13 \%$ of the energy and the N.P.U. ranged from 25 to $100 \%$; however, the mean N.D-p.V. calculated on the basis of energy was $4.0 \%$ with a standard deviation of only \pm 0.82 . If this value is taken to be constant it is possible to calculate the percentage of protein calories in a diet required for maintenance $\left(P_{m}\right)$ for any given N.P.U.(st.) : the values are shown in Fig. I.

$$
P_{m}=\frac{4^{\circ 0}}{\text { N.P.U.(st.) }} \times \text { 100. }
$$

For example, $P_{m}$ for a diet based on a protein with a N.P.U.(st). of roo would be $4 \%$; this is in accordance with the level of egg protein adopted by Mitchell \& Carman (I926) for measurements of endogenous nitrogen; also for wheat gluten (N.P.U.(st.) $=40$ ), $P_{m}=10 \%$, and for protein such as blood and gelatin (N.P.U.(st.) $=0$ ), $P_{m}$ is never reached.

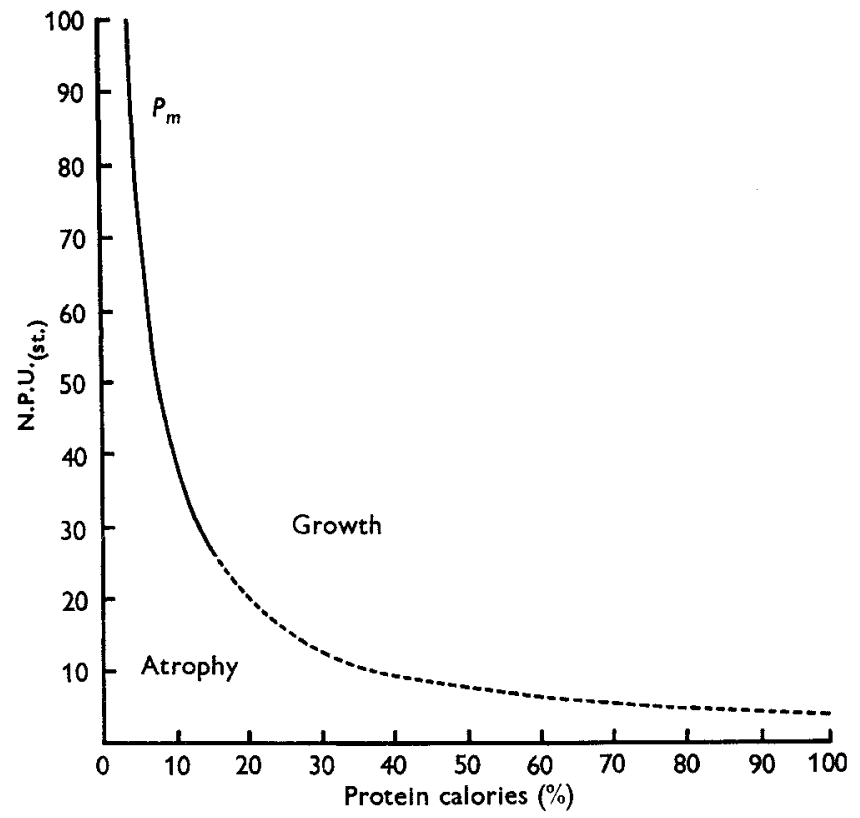

Fig. I. Calculated values for the percentage of energy provided by protein in diets supplying requirements for maintenance $\left(P_{m}\right)$ for proteins having any given N.P.U.(st.). The broken line indicates the extrapolated region.

$$
\text { N.P.U.(op.) and protein content }
$$

N.P.U.(op.) values were determined for three different proteins-wheat gluten, casein and freeze-dried beef-fed at concentrations ranging from that required for maintenance up to $45 \%$ protein calories. The relationship between N.P.U.(op.) and the level 
of protein fed was always substantially linear. The regression lines derived from the three sets of values are plotted in Fig. 2. Where $P$ is the percentage of protein calories in the diet, the equations were

for wheat gluten: N.P.U.(op.) $=44.8-0.79 P \quad(r=0.85)$,

for casein:

N.P.U.(op.) $=75.6-1.39 P \quad(r=0.86)$,

for beef powder: N.P.U.(op.) $=88.3-\mathrm{I} \cdot 68 P \quad(r=0.86)$.
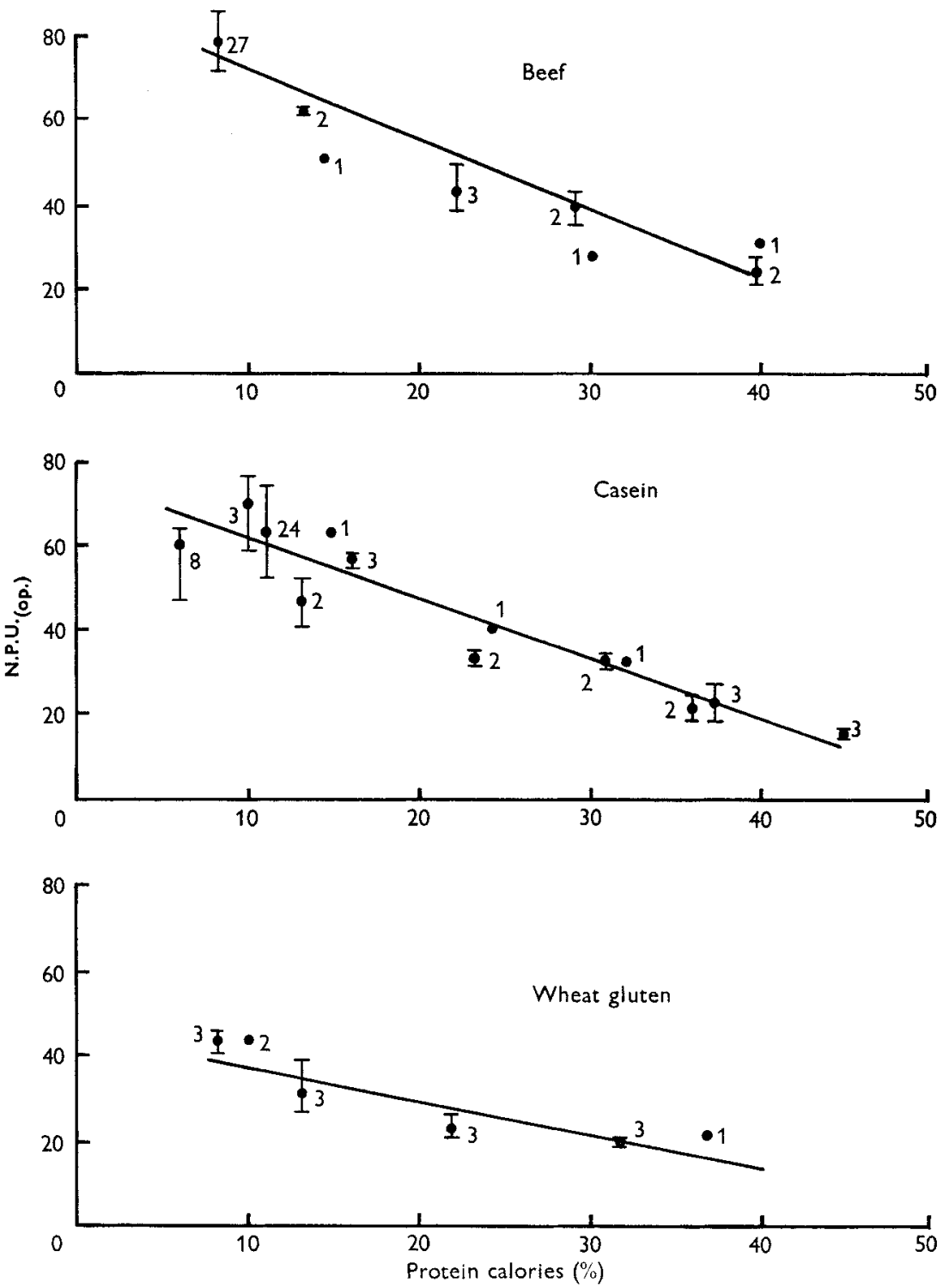

Fig. 2. N.P.U.(op.) of beef powder, casein and wheat gluten at different concentrations in the diet. The numerals show the number of independent trials made at each concentration and the vertical lines the range of values of N.P.U.(op.). 
The results from experiments with diets in which more than $50 \%$ of the energy was supplied by protein are not reported here in detail as these diets were unable to support growth in the rat. They showed that not only were the N.P.U. values approximately equal for the three proteins, but that despite the high protein content the N.D-p.v.'s approximated to that required for maintenance.

The protein values of a number of human diets with a wide range of protein content were also determined for the purpose of testing the prediction method presented below, and are given in Table 3. A comparison is made with protein values calculated from protein scores based on amino-acid analysis.

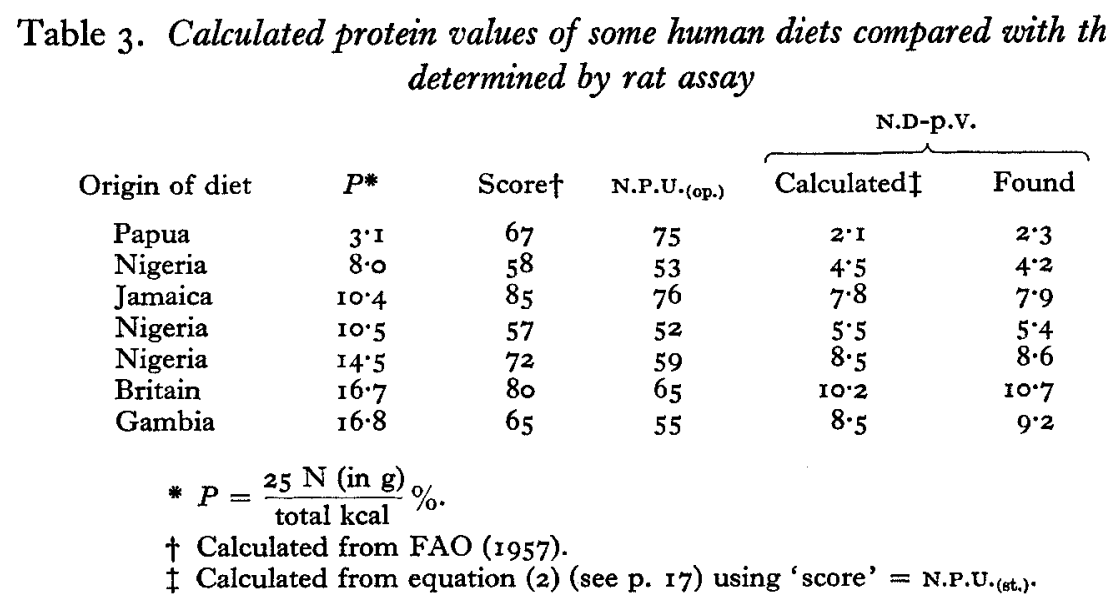

\section{DISCUSSION}

\section{Development of prediction equation}

For the purpose of prediction of protein values it is necessary to consider regions above and below maintenance separately. In Fig. 3 are curves derived from values presented in this paper, and a mathematical interpretation of the results is proposed below.

It is generally agreed that N.P.U. is constant at and below the concentration of protein in the diet required to achieve maintenance; indeed, the method of Allison \& Anderson (1945) is based on the fact that the relation between $\mathrm{N}$ balance and $\mathrm{N}$ intake is linear in this region. For the purposes of predicting protein values a constant characteristic of the proteins fed is required, which can be related to chemical data ('score'). Much discussion (Anonymous, 1959) has centred on the best protein level for the biological assay of proteins, and compromises between 8 and $15 \%$ have been chosen by various authors. From Figs. I and 3 it is clear that the region of maximum N.P.U. will occur at different levels depending upon the protein fed; thus the value for beef powder will be a maximum from o to $5 \%$ and for wheat gluten from o to $1 \mathrm{\%} \%$. In view of the fact that above these protein concentrations N.P.U. falls, we propose that the standardized value is equal to the maximum value and may be measured directly at or below maintenance. As the accuracy of most biological assays is greater at higher levels of $\mathrm{N}$ 
intake (Mitchell, Burroughs \& Beadles, 1936), it may be better as an alternative to measure N.P.U.(op.) at such levels and calculate N.P.U.(st.) from the equations below or by reference to Fig. 3 .

It is evident from the above discussion that maximum efficiency of $\mathrm{N}$ utilization will be achieved at progressively lower levels of $\mathrm{N}$ in the diet as the N.P.U.(st.) of the protein

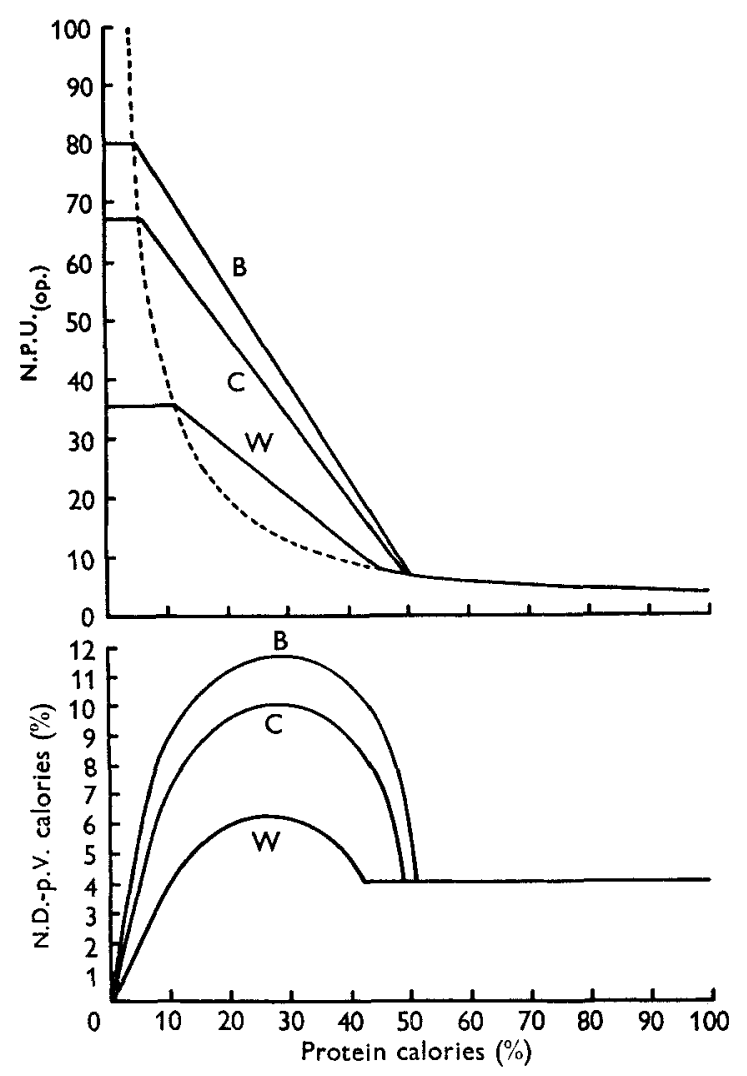

Fig. 3. Diagram showing the relationship between N.P.U.(op.) and N.D-p.v., with protein concentration for three proteins. $\mathrm{B}$, beef powder; $\mathrm{C}$, casein; $\mathrm{W}$, wheat gluten. $\mathrm{B}, \mathrm{C}$ and $\mathrm{W}$ have protein scores of 80,67 and 35 .

is raised. It follows that, with balanced amino-acid mixtures, maximum utilization will only be achieved at low protein: calorie ratios. In the experiments of Rose (1949) on man a calorie intake of $4400 \mathrm{kcal}$ was required to obtain $\mathrm{N}$ equilibrium when $7 \mathrm{~g} \mathrm{~N}$ were given, which corresponds to a diet containing $4 \%$ of protein calories. Rose (1957) could give no explanation for the high calorie requirement, but it is clear from the work presented here that a lower calorie intake corresponds to a protein:calorie ratio above $4 \%$, resulting in incomplete utilization and hence a negative $\mathrm{N}$ balance.

The protein values above maintenance fall with increase in protein concentration in the diet. Fig. 3 shows that the rates of fall are different for different proteins. However, it is possible to find common factors in the regression equations for the three proteins 
so that a general equation may be derived. If the regression equations are put in a new form

$$
\begin{aligned}
& \text { for beef powder: N.P.U.(op.) }=88 \cdot 3\left(\mathrm{x}-\frac{P}{5^{2 \cdot 6}}\right), \\
& \text { for casein: } \quad \text { N.P.U.(op.) }=75 \cdot 6\left(\mathrm{I}-\frac{P}{54 \cdot 4}\right), \\
& \text { for wheat gluten: N.P.U.(op.) }=44 \cdot 8\left(1-\frac{P}{56 \cdot 7}\right),
\end{aligned}
$$

the values for the coefficients of $P$ inside the parentheses for the three proteins of widely differing amino-acid composition are very similar and approximate to $\frac{1}{54}$.

Forbes, Vaughan \& Yohe (1958) give three equations for the regression of the percentage of protein in the diet on biological value for egg, casein and groundnut, with the comment that prediction is only possible with 'the biological value determined at a specified level and knowledge of the slope of the line appropriate to the determined biological value'. However, by making a correction for the calorie content of their diets and expressing their equations in the form presented above, values are obtained for the coefficient of $P$ equal to $\frac{1}{43}$ (egg), $\frac{1}{51}$ (casein) and $\frac{1}{53}$ (groundnut). In view of the fact that these authors used a different method, with depleted and not normal rats of a different strain, the agreement is very encouraging.

In the regression equations in the new form the terms outside the parentheses represent the intercepts of the regression lines on the N.P.U. axis. From the preceding discussion and by inspection of Fig. 3, it is clear that these intercepts are not N.P.U.(st.) which is a constant below the maintenance hyperbola. In order to generalize the regression equations, it is necessary to express these intercepts in terms of N.P.U.(st.)They may be shown to be*

$$
\frac{\text { N.P.U.(st.) }}{\mathrm{I}-\left(P_{m} / 54\right)}
$$

Thus the general equation may be written

$$
\begin{aligned}
\text { N.P.U.(op.) } & =\frac{\text { N.P.U.(st.) }}{\mathrm{I}-\left(P_{m} / 54\right)} \times\left(\mathrm{I}-\frac{P}{54}\right) \\
& =\text { N.P.U.(st.) } \\
& \frac{54-P}{54-P_{m}} . \\
\text { N.D-p.V. } & =\text { N.P.U.(op.) }_{\text {(op }} \times P \\
& =\text { N.P.U.(st.) } \\
&
\end{aligned}
$$

* Let the intercept $=C$.

The regression equation is N.P.U.(op.) $=C\{\mathrm{I}-(P / 54)\}$.

At maintenance $P=P_{m}$ and N.P.U. (op.) $_{\text {(o. }}=$ N.P.U.(st.) $)$.

Thus N.P.U.(st.) $=C\left\{1-\left(P_{m} / 54\right)\right\}$.

$$
\therefore C=\frac{\text { N.P.U.(st.) }}{\mathrm{I}-\left(P_{m} / 54\right)} \text {. }
$$




\section{Application of prediction equation}

The curves relating N.P.U.(op.) and N.D-p.v. with protein concentration over the complete range are given in Fig. 3. It should be remembered that they were derived from values obtained for young growing rats fed $a d l i b$. Such animals have a high $\mathrm{N}$ demand and the values obtained must be regarded as maximum. Application of the equations to diets fed to animals in different physiological or pathological states should be made with due caution, but it would seem reasonable to regard values thus calculated as representing the potential nutritive value of the diet. Differentiation of equation 2 with respect to $P$ and equating to zero gives a maximum N.D-p.v. for a given N.P.U.(st.) at $27 \%$ protein calories. For egg protein this yields a N.D-p.v. of $14.6 \%$, which may be regarded as the highest protein value possible.

The observed value for the coefficient of $P$ inside the parentheses is of some interest: the regression lines tend to converge at $54 \%$ protein calories rather than at $100 \%$, as might be expected if protein and non-protein calories were of equal value to the animal for metabolic energy purposes. However, the high specific dynamic action of proteins indicates that it is not so, and it is of interest that, according to Brody (1945), for every $100 \mathrm{kcal}$ of protein $40 \mathrm{kcal}$ may be expected as heat, leaving only $60 \mathrm{kcal}$ for other purposes; this value approximates to the point of intersection of the regression lines, 54, which is the reciprocal of the coefficient of $P$ inside the parentheses (see p. 17).

Equations $I$ and 2 may be used to predict the protein value of diets from chemical data, provided a satisfactory method is used to estimate N.P.U.(st.). Many are available for this purpose, but most are valid only in specific circumstances. In Table 3 calculations using the method outlined by FAO (1957) are presented. The diets have been scored by direct analysis, but this method takes no account of the possible limited availability of the amino acids to the animal, or indeed of the other factors which influence protein value and which have been discussed earlier. Nevertheless, despite a divergence between 'score' and N.P.U..(op.), the values for N.D-p.v. calculated from equation 2 show good agreement with those determined biologically.

\section{SUMMARY}

I. A method is presented, allowing for variations in protein concentration, for the prediction of the protein value of diets from analytical data: for this purpose it is essential to express the dietary values in terms of the proportion of the energy in the diet contributed by protein.

2. The net dietary-protein value required for maintenance is $4 \%$ of the total calories; the percentage of protein calories of maintenance diets is given by $P_{m}=(400 /$ score), where the score is a satisfactory estimate of net protein utilization (standardized).

3. For diets having N.D-p.v. greater than $4 \%$ of the calories (i.e. when score $\times P>4$ ), the equation relating N.D-p.v. at different protein levels is

$$
\text { N.D-p.v. }=P \times \text { score }\left(\frac{54-P}{54-P_{m}}\right),
$$

where $P$ is the percentage of protein calories in the diet. 
We wish to thank our colleague, $\mathrm{Mr} \mathrm{O}$. A. M. Lewis, for allowing us to use aminoacid values determined by him, using column chromatography; and Miss H. Sheppard for much of the work with the animals.

\section{REFERENCES}

Allison, J. B. \& Anderson, J. A. (1945). F. Nutr. 29, 413.

Anonymous (1959). Nutr. Rev. 17, 307.

Brody, S. (1945). Bioenergetics and Growth. New York: Reinhold Publishing Corporation.

Drury, E. A. \& Miller, D. S. (1959). Proc. Nutr. Soc. 18, xxvi.

FAO (1957). FAO nutr. Stud. no. I6.

Forbes, R. M., Vaughan, L. \& Yohe, M. (1958). F. Nutr. 64, 291.

Miller, D. S. \& Bender, A. E. (1955). Brit. F. Nutr. 9, 382.

Miller, D. S. \& Payne, P. R. (1959). Brit. F. Nutr. r3, 501.

Mitchell, H. H., Burroughs, W. \& Beadles, J. R. (I936). F. Nutr. rI, 257.

Mitchell, H. H. \& Carman, G. G. (1926). F. biol. Chem. 63, 133 .

Platt, B. S. \& Miller, D. S. (1958). Proc. Nutr. Soc. 17, ro6.

Platt, B. S. \& Miller, D. S. (1959). Proc. Nutr. Soc. r8, vii.

Rose, W. C. (1949). Fed. Proc. 8, 546.

Rose, W. C. (1957). Human Protein Requirements and their Fulfilment in Practice. Proceedings of a Conference in Princetown, United States (1955) Sponsored Fointly by FAO/WHO/Fosiah Macy Fr. Foundation, p. ro. (J. C. Waterlow and J. M. L. Stephen, editors.) Rome: Food and Agriculture Organization of the United Nations. 